\title{
Giant angiolymphoid hyperplasia with eosinophilia on the chest
}

Angiolymphoid hyperplasia with eosinophilia is a rare vascular proliferation characterized by single or multiple purplish, brownish papules and subcutaneous nodules, sometimes associated with pain or pruritus. This rare benign process occurs with a female predominance. Approximately $85 \%$ of the lesions occur in the skin of the head and neck; most of them are around the ear or on the forehead or scalp. Whether angiolymphoid hyperplasia with eosinophilia represents a benign neoplasm or an unusual reaction to varied stimuli, including trauma, the etiology remains unclear. Histopathologically, the lesions consist of a proliferation of blood vessels of variable size lined by large epithelioid endothelial cells and a variable inflammatory infiltrate of lymphocytes and eosinophils, sometimes with lymphoid follicle formation. The lesion is benign but may be persistent and is difficult to eradicate. We report on a case of a 58-year-old Caucasian man who presented a purplish pink dome-shaped tumor of size up to $8 \mathrm{~cm}$ in diameter located on the chest. We emphasize this case considering the unusual dimensions of the lesion (8 $\mathrm{cm}$ diameter) and the atypical location on the chest.

Trindade F, Haro R, Requena L. Giant angiolymphoid hyperplasia with eosinophilia on the chest.

J Cutan Pathol 2009; 36: 493-496. (C) 2008 Blackwell Munksgaard.

\section{Felicidade Trindade ${ }^{1}$, Rosario Haro $^{2}$ and Luis Requena ${ }^{2}$}

${ }^{1}$ Department of Dermatology, Hospital dos Capuchos, Lisbon, Portugal and

²Department of Dermatology, Fundación

Jiménez Díaz, Universidad Autónoma, Madrid, Spain

Felicidade Trindade, MD, Department of Dermatology, Hospital dos Capuchos, Alameda Santo António dos Capuchos, 1169-050 Lisbon, Portugal

Tel: +351213136300

Fax: +35121356 2208

e-mail: felicidade.trindade@gmail.com

Accepted for publication May 1, 2008
The term 'histiocytoid hemangioma', initially coined by Rosai et al., ${ }^{1}$ embraced several cutaneous and extracutaneous vascular proliferations, both benign and malignant, characterized by the proliferation of histiocytoid endothelial cells.

Angiolymphoid hyperplasia with eosinophilia was originally described by Wells and Whimster ${ }^{2}$ in 1969 as 'subcutaneous angiolymphoid hyperplasia with eosinophilia'. They first linked this disorder to Kimura's disease because they considered angiolymphoid hyperplasia with eosinophilia as a late stage of Kimura's disease. The rare occurrence of Kimura's disease in White patients caused the confusion between Kimura's disease and angiolymphoid hyperplasia with eosinophilia. ${ }^{3}$ Rosai et al. ${ }^{1}$ were the first to note that Kimura's disease and angiolymphoid hyperplasia with eosinophilia are actually two different clinicopathological entities.

Because of its historical denomination and its reactive nature, probably as a consequence of an arteriovenous shunt, angiolymphoid hyperplasia with eosinophilia is included within the group of vascular hyperplasias. ${ }^{4}$

It has been described with different names by different authors, including atypical pyogenic granuloma ${ }^{5}$ pseudopyogenic granuloma, ${ }^{6}$ inflammatory angiomatous nodule, ${ }^{6}$ inflammatory arteriovenous hemangioma, ${ }^{7}$ papular angioplasia, ${ }^{8}$ intravenous atypical vascular proliferation, ${ }^{9}$ epithelioid hemangioma ${ }^{10}$ and cutaneous histiocytoid hemangioma. ${ }^{1}$

We report on a large solitary lesion of angiolymphoid hyperplasia with eosinophilia involving the chest. The location and the large size of the lesion were the two most striking characteristics of this case.

\section{Case report}

A 58-year-old Caucasian man presented with a tumor located in the thorax. The lesion arose during the past 6 months and had always been asymptomatic. 


\section{Trindade et al.}

Physical examination revealed a purplish pink dome-shaped tumor of size up to $8 \mathrm{~cm}$ in diameter (Fig. 1). The tumor was surrounded by a peripheral hyperpigmented brownish halo, which showed a size of $12 \mathrm{~cm}$ in diameter.

Routine blood tests including peripheral eosinophil count revealed normal results.

The lesion was surgically removed, and histological examination showed a prominent proliferation of blood vessels with variable size and shape involving the full thickness of the dermis. The thickness of the vessel walls was also variable, but a common finding consisted of plump endothelial cells lining the vascular lumina (Fig. 2). Some of the endothelial cells showed cytoplasmic vacuoles as expression of primitive vascular differentiation. Around the vessels, there was fibrillary fibroplasia and an inflammatory infiltrate with abundant number of lymphocytes and eosinophils (Fig. 3). At the periphery, which corresponded clinically with the peripheral macular brown halo, the lesion was composed mostly by a proliferation of small thin-walled capillary blood vessels with abundant deposits of hemosiderin in the stroma. A diagnosis of angiolymphoid hyperplasia with eosinophilia was established.

At the 3-months follow up, there was no evidence of tumor recurrence or metastatic disease.

\section{Discussion}

Angiolymphoid hyperplasia with eosinophilia is a rare benign vascular proliferation that manifests in adults as solitary or multiple purplish, brownish papules, plaques or nodules. It has different presentations resulting in various clinical impressions. In a study of 116 patients by Olsen and Helwig, ${ }^{11}$ the most common clinical diagnoses were epidermal cysts and hemangiomas.

The lesions occur in the head and neck; most of them are on or near the periauricular region, forehead or scalp. ${ }^{11}$ Rare sites of involvement include

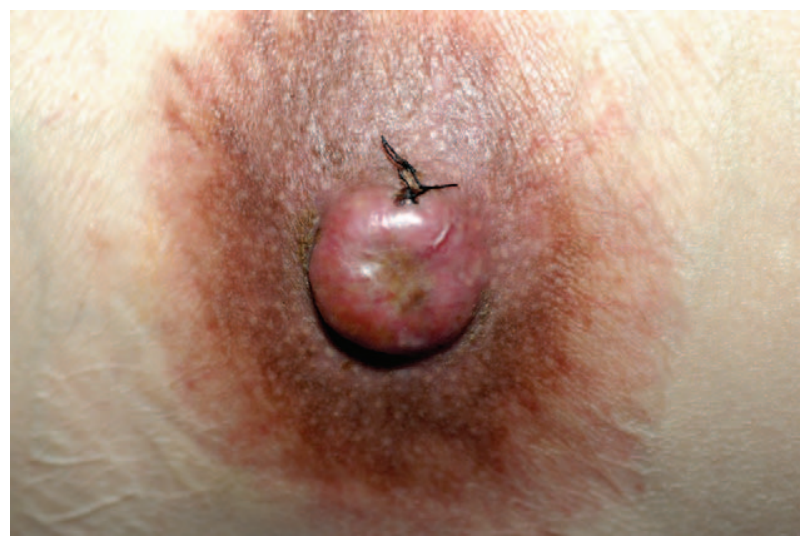

Fig. 1. Clinical appearance of the tumor located in the thorax size up to $8 \mathrm{~cm}$ in diameter.

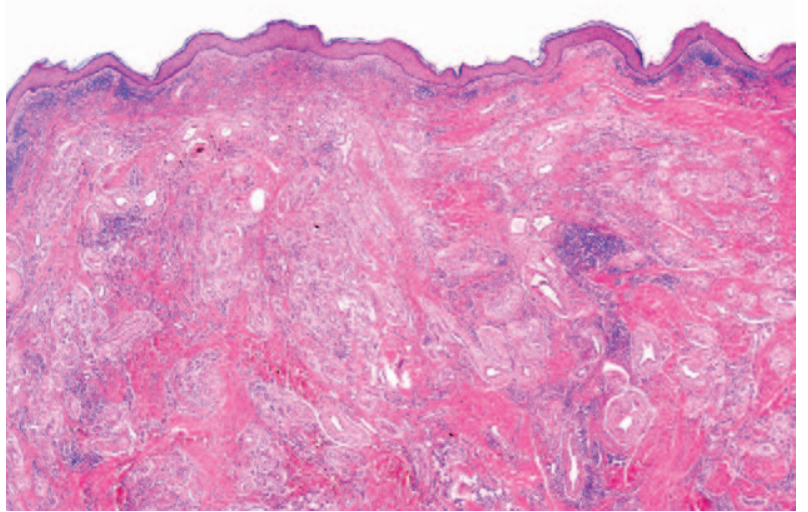

Fig. 2. Scanning power showing the histopathological features of angiolymphoid hyperplasia with eosinophilia. Thick-walled blood vessels with protuberant endothelium and a prominent inflammatory infiltrate composed of lymphocytes and eosinophils (hematoxylineosin stain; original magnification $\times 10$ ).

the hands, shoulders, breasts, penis, vulva and oral mucosa. ${ }^{1-15}$ It has also been described in other tissues, including liver, orbit, spleen, palate, bone, heart and blood vessels. It is associated with peripheral blood eosinophilia of $6-34 \%$ in about $20 \%$ of patients. ${ }^{11}$

Approximately $80 \%$ of patients present with isolated lesions, while the remaining patients usually show grouped papules or nodules in a single region. ${ }^{16}$ They are often pruritic or painful and may coalesce into confluent chronic plaques, with little propensity for spontaneous resolution. ${ }^{11}$

Most intradermal lesions are small, with diameters of $0.5-2 \mathrm{~cm}$, with a range of $0.2-8 \mathrm{~cm}$. Larger nodules tend to be deeply situated within the subcutis, up to $5-10 \mathrm{~cm}$ in diameter. ${ }^{11}$

Angiolymphoid hyperplasia with eosinophilia is seen most commonly in Asians followed by White

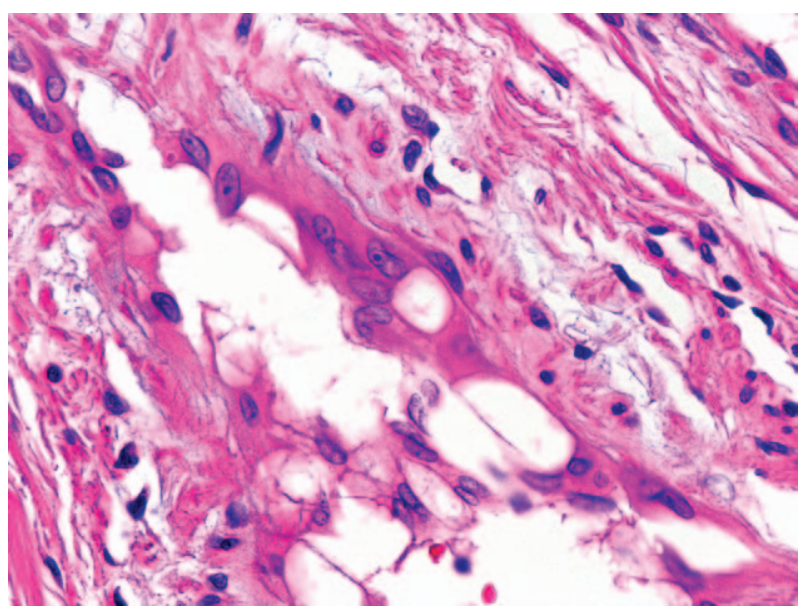

Fig. 3. Higher magnification showing the histopathological characteristics of the vessels surrounded by a perivascular and interstitial inflammatory infiltrate mostly composed of lymphocytes and eosinophils (hematoxylin-eosin stain; original magnification $\times 200$ ). 
Giant angiolymphoid hyperplasia

people. It is slightly more common in females ${ }^{16}$ and usually present in patients aged 20-50 years, with mean onset of 30-33 years. The lesions can persist but serious complications (e.g. malignant transformation) do not occur. ${ }^{17}$

The origin of the disease is not known; numerous factors suggest that it is an unusual reactive process. Infection (human $\mathrm{T}$ lymphotropic virus or human herpesvirus 8), hormonal background or possible role of trauma is the mostly discussed possibilities. Increased expression of vascular endothelial growth factor and interleukin 5 was detected in some cases. ${ }^{18}$

When the biopsy incision is large and sufficiently deep, an arteriovenous shunt is found in a significant percentage of the cases. ${ }^{19}$ These features suggest that angiolymphoid hyperplasia with eosinophilia is not neoplastic in nature, but arises from a reactive hyperplastic process probably as a result of damage and repair of an artery or vein. ${ }^{10}$

Higher prevalence of the disease among women and occurrence of the disease in association with sex hormones are two important observations supporting that sex hormones may play a role in the pathogenesis of angiolymphoid hyperplasia with eosinophilia. ${ }^{19}$

Kimura's disease was earlier thought to be related to angiolymphoid hyperplasia with eosinophilia, but nowadays, it is considered a different clinical entity. ${ }^{3}$ The disorder was originally described by Kimura et al. in 1948 as 'an unusual granulation combined with hyperplastic changes of lymphatic tissue'. ${ }^{20}$

In particular, Kimura's disease predominantly affects young males of Asian descent. ${ }^{21}$ This disorder is frequently accompanied by enlarged regional lymph nodes with or without an associated soft tissue mass, high incidence of peripheral blood eosinophilia and elevated serum immunoglobulin E levels. ${ }^{3}$

Angiolymphoid hyperplasia with eosinophilia shows characteristic histopathological features, including a proliferation of irregular thick-walled blood vessels, many of which lined by enlarged endothelial cells with uniform ovoid nuclei and intracytoplasmic vacuoles. ${ }^{17}$ Walls of the aberrant vessels often have smooth muscle and abundant mucin. Endothelial proliferative cells with epithelioid appearance may also appear as solid aggregations disposed in sheets, and the angiomatous nature of the lesion is less evident. ${ }^{4}$ These plump endothelial cells are characteristic of this condition, and they have been named by different authors as histiocytoid, epithelioid or hobnail endothelial cells. ${ }^{4}$ The hobnail cells protrude prominently into the lumina of the vessels, and intravascular proliferation of them may be seen in the lumina of larger vessels. In addition, a perivascular and interstitial infiltrate composed primarily of lymphocytes and eosinophils is present. Eosinophils typically comprise $5-15 \%$ of the infiltrate. Rarely, they can account for as much as $50 \%$ of the infiltrate. ${ }^{17}$ Occasionally, the infiltrate is devoid of eosinophils. In some cases, lymphoid follicles with germinal centers are present, but usually, they are not as prominent as in Kimura's disease. ${ }^{4}$ Endothelial cells are positive for factor VIII-related antigen, ${ }^{10}$ Ulex europaeus I lectin, ${ }^{14} \mathrm{CD} 34,{ }^{22} \mathrm{CD} 31^{22}$ and vimentin. ${ }^{22}$ Ultrastructural studies showed WeibelPalade bodies in the endothelial cells. ${ }^{22}$

Lesions of angiolymphoid hyperplasia with eosinophilia can remit over the course of months or years, but they tend to persist or recur. There is no consistently effective treatment for this disease. Intralesional corticosteroids and irradiation are among the modalities used. Other treatments that have been reported include topical imiquimod, topical tacrolimus and interferon alfa-2b. ${ }^{17,23}$ Although surgical excision can be curative, recurrences are common. Deep surgical excision that includes the arterial and venous segments at the base of the lesion has been reported to have the most favorable results, with no reported recurrence after 1-year follow up. ${ }^{23}$

Destructive techniques such as cryotherapy and electrodessication may be attempted. In addition, pulsed dye lasers have been used to selectively target the vasculoproliferative component of this disorder. ${ }^{24}$ Multiple laser treatments are generally necessary to cause resolution. The use of a long-pulse turntable dye laser has been advocated based on its deeper penetration and greater epidermal sparing properties.

We emphasize this case considering the unusual dimensions of the tumor $(8 \mathrm{~cm}$ diameter $)$ and the atypical location on the chest.

\section{References}

1. Rosai J, Gold J, Landy R. The histiocytoid hemangiomas: a unifying concept embracing several previously described entities of skin, soft tissue, large vessels, bone, and heart. Hum Pathol 1979; 10: 707.

2. Wells GC, Whimster IW. Subcutaneous angiolymphoid hyperplasia with eosinophilia. Br J Dermatol 1969; 81: 1.

3. Requena L, Sangueza OP. Cutaneous vascular proliferations. Part III. Malignant neoplasms, other cutaneous neoplasms with significant vascular component, and disorders erroneously considered as vascular neoplasms. J Am Acad Dermatol 1998; 38: 143.

4. Requena L, Sangueza OP. Cutaneous vascular proliferations. Part II. Hyperplasias and benign neoplasms. J Am Acad Dermatol 1997; 37: 887.

5. Peterson WG, Fusaro RM, Goltz RW. Atypical pyogenic granuloma: a case of benign hemangioendotheliomatosis. Arch Dermatol 1964; 90: 197.

6. Wilson Jones E, Bleehen SS. Inflammatory angiomatous nodules with abnormal blood vessels occurring about the ears and scalp (pseudo- or atypical pyogenic granuloma). Br J Dermatol 1969; 81: 804.

7. Girard C, Graham JH, Johnson WC. Arteriovenous hemangioma (arteriovenous shunt): a clinicopathological and histochemical study. J Cutan Pathol 1974; 1: 73. 


\section{Trindade et al.}

8. Jones E, Marks R. Papular angioplasia: vascular papules of the face and scalp simulating malignant vascular tumors. Arch Dermatol 1970; 102: 422.

9. Rosai J, Ackerman LR. Intravenous atypical vascular proliferation: a cutaneous lesion simulating a malignant blood vessel tumor. Arch Dermatol 1974; 109: 714.

10. Fetsch JF, Weiss SW. Observations concerning the pathogenesis of epithelioid hemangioma (angiolymphoid hyperplasia). Mod Pathol 1991; 4: 449.

11. Olsen TG, Helwig EB. Angiolymphoid hyperplasia with eosinophilia: a clinicopathologic study of 116 patients. J Am Acad Dermatol 1985; 12: 781.

12. Castro C, Winkelmann RK. Angiolymphoid hyperplasia with eosinophilia in the skin. Cancer 1974; 34: 1696.

13. Aguilar A, Ambrojo P, Requena L, Olmos L, Sanchez Yus E. Angiolymphoid hyperplasia with eosinophilia limited to the vulva. Clin Exp Dermatol 1990; 15: 65.

14. Srigley JR, Ayala AG, Ordoñez NG, et al. Epithelioid hemangioma of the penis: a rare and distinctive vascular lesion. Arch Pathol Lab Med 1985; 109: 51.

15. Masa FC, Fretzin DF, Chowdhury L, et al. Angiolymphoid hyperplasia demonstrating extensive skin and mucosal lesions controlled with vinblastine therapy. J Am Acad Dermatol 1984; 11: 333 .

16. Weiss SW, Goldblum JR. Benign tumors and tumor-like lesions of blood vessels. In Enzinger FM, Weiss SW, eds. Soft tissue tumors. 4th ed. Philadelphia, PA: CV Mosby Co, 2001; 856.
17. Glusac E. Angiolymphoid hyperplasia with eosinophilia. eMedicine 2002. URL http://www.emedicine.com/derm/topic30. htm [accessed on 28 January 2004].

18. Aoki M, Kimura Y. Angiolymphoid hyperplasia with eosinophilia associated with anomaluos dilatation of occipital artery: iL-5 and VEGF expression of lesional mast cells. Arch Dermatol 2002; 138: 982.

19. Zarrin-Kameh N, Spoden JE, Tran RM. Angiolymphoid hyperplasia with eosinophilia associated with pregnancy: a case report and review of the literature. Arch Pathol Lab Med 2005; 129: 1168.

20. Kimura T, Yoshimura S, Ishikama E. On the unusual granulation combined with hyperplastic changes of lymphatic tissues. Trans Soc Pathol Jpn 1948; 37: 178.

21. Kung ITM, Gibson JB, Bannatyne PM. Kimura's disease: a clinicopathological study of 21 cases and its distinction from angiolymphoid hyperplasia with eosinophilia. Pathology 1984; 16: 39.

22. Angervall L, Kindblom LG, Karlsson K, et al. Atypical hemangioendothelioma of venous origin: a clinicopathologic angiographic immunohistochemical and ultrastructural study of two endothelial tumors within the concept of histiocytoid hemangioma. Am J Surg Pathol 1985; 9: 504.

23. Baum EW, Sams WM Jr, Monheit GD. Angiolymphoid hyperplasia with eosinophilia: the disease and a comparison of treatment modalities. J Dermatol Surg Oncol 1982; 8: 966.

24. Papadavid E, Krausz T, Chu AC, Walker NPJ. Angiolymphoid hyperplasia with eosinophilia successfully treated with the flashlamp pulsed-dye laser. Br J Dermatol 2000; 142: 192. 